Annales Geophysicae (2003) 21: 627-637 (C) European Geosciences Union 2003

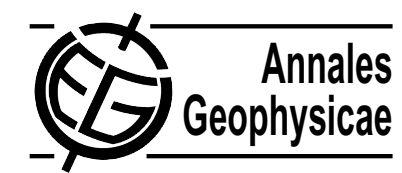

\title{
On ALADIN precipitation modeling and validation in an Alpine watershed
}

\author{
B. Ahrens ${ }^{1}$, K. Jasper ${ }^{2}$, and J. Gurtz ${ }^{2}$ \\ ${ }^{1}$ Institute for Meteorology and Geophysics, University of Vienna, Austria \\ ${ }^{2}$ Institute for Atmospheric and Climate Research, ETH Zürich, Switzerland
}

Received: 31 October 2001 - Revised: 1 July 2002 - Accepted: 20 September 2002

\begin{abstract}
Highly resolved precipitation forecasts are necessary in many applications, especially in mountain meteorology and flash flood forecasts for small- to medium-sized alpine watersheds. Here we present precipitation forecasts simulated by the limited area model ALADIN applying different grid resolutions $(\Delta x=10 \mathrm{~km}$ and $4 \mathrm{~km})$. Target area of the investigations is the Alpine Ticino-Verzasca-Maggia watershed (total area: $2627 \mathrm{~km}^{2}$ ).

We discuss problems of validation of high-resolution precipitation forecasts by comparison with observed precipitation fields and apply an indirect validation approach by using ALADIN forecasts as input to hydrologic simulations. These simulations are carried out with the distributed hydrologic model WaSiM-ETH $(\Delta x=500 \mathrm{~m}, \Delta t=1 \mathrm{~h})$. The time step of meteorological input to WaSiM-ETH is fixed at $1 \mathrm{~h}$ but spatial resolution varies.

The main result of the validation experiments for three heavy precipitation events is, that coarser-scale ALADIN forecasts (in model version 11.2) provide better precipitation predictors for hydrologic modeling than higher-resolution forecasts. The experiments demonstrate that hydrologic modeling is a promising tool for the evaluation of highresolution precipitation fields.
\end{abstract}

Key words. Hydrology (floods) - Meteorology and atmospheric dynamics (mesoscale meteorology; precipitation)

\section{Introduction}

Nowadays, limited area models (LAMs) provide meteorological forecasts with horizontal grid spacing of only a few kilometers; grid spacing will decrease further in the coming years caused by progress in high-performance computing (Benoit et al., 2002; Schär, 2001). An example of the application of high-resolution meteorological forecasts is input supply to flood forecasts for small- to medium-sized (up to a few thousand square-kilometers) alpine catchments (see,

Correspondence to: B. Ahrens (Bodo.Ahrens@univie.ac.at) e.g. Bacchi and Ranzi, 2000; Benoit et al., 2000). In the case of flood-forecasts in mountainous watersheds, the most important meteorological input is precipitation. Small errors in storm tracks and precipitation amounts readily translate into large errors in computed hydrographs (Jasper et al., 2000). This is problematic since precipitation processes are highly parameterized in meteorological models and thus precipitation forecast quantities are most uncertain (see, e.g. Lau et al., 1996).

If meteorological forecasts are used as input for hydrologic simulations, there is substantial error propagation. Therefore, atmospheric models have to be validated and errors have to be quantified. The most important validation method is comparison of meteorological simulation results with meteorological observations. But, application of this validation method is difficult for high-resolution precipitation fields. For example, a recent analysis of precipitation for the European Alpes by Frei and Häller (2001) (cf. Fig. 1) has a time resolution of $24 \mathrm{~h}$ and a spatial grid of about $25 \mathrm{~km}$ with regionally even lower effective resolution depending on the available surface station network. This type of analysis is useful for model validation on a $100 \mathrm{~km}$-scale (see, e.g. Ahrens et al., 1998; Ferretti et al., 2000), but not on a kilometer-scale. Direct validation with station data is a problem because of the different spatial support of simulated (several tens of square-kilometers) and measured $\left(\sim 1 \mathrm{~m}^{2}\right)$ precipitation data. The validation results are strongly influenced by the variability of the precipitation within model grid boxes. This scale problem in validation is discussed in, for example, Tustison et al. (2001); Cherubini et al. (2002). Another challenge is the correction of rain gauge data for systematic errors which can be due to wind-induced or evaporation loss (Rubel and Hantel, 1999). Validation with highresolution remote sensing data, in particular radar data, is difficult because of the relatively large measurement uncertainties (e.g. Ciach et al., 2000; Adler et al., 2001).

This study focuses on precipitation simulations with the LAM ALADIN, a joint development of several European national weather agencies (please have a look at 


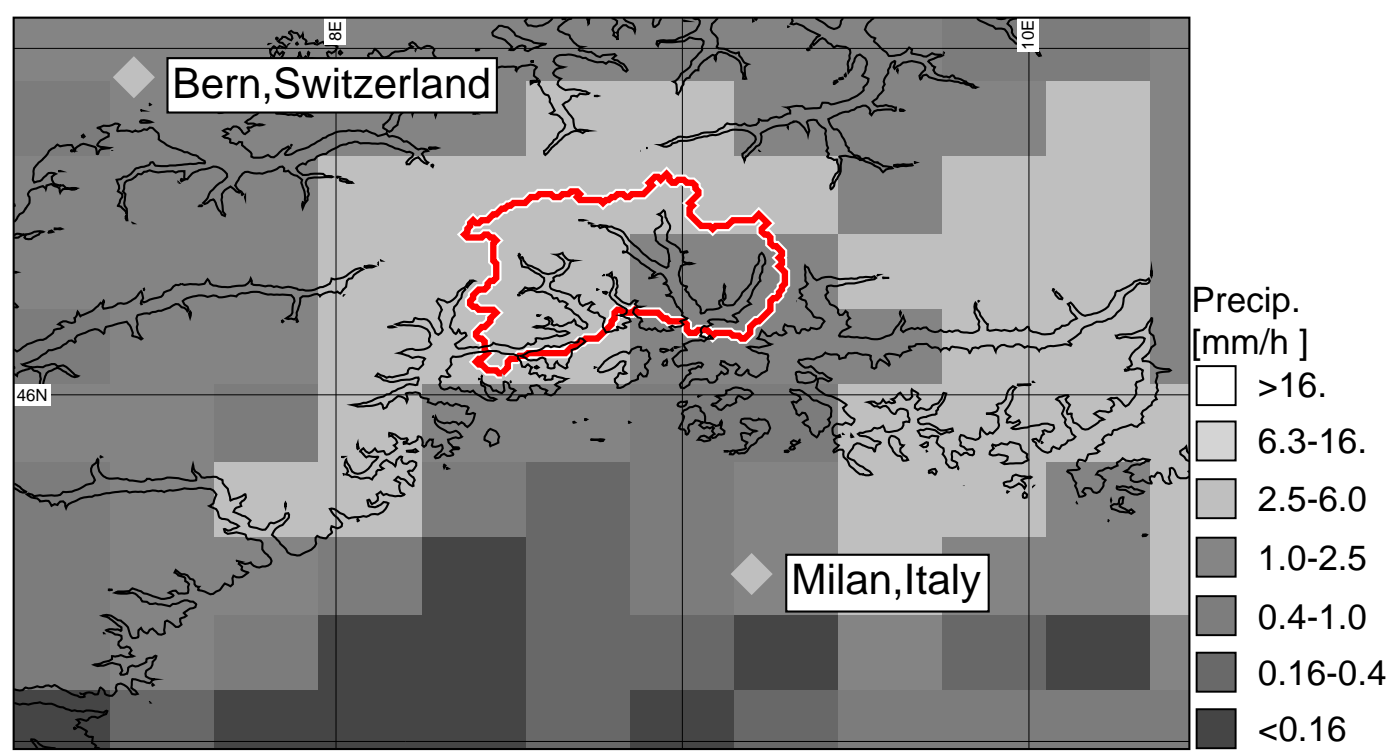

Fig. 1. Specification of areas of interests. The Ticino-Verzasca-Maggia (TVM) watershed (total area: $2627 \mathrm{~km}^{2}$ ) is outlined in red. The complex orography in the area is indicated by $1000 \mathrm{~m}$ ASL thin isolines. Additionally, a precipitation analysis by Frei and Häller (2001) for the period 06:00 UTC at 20 September 1999 to 06:00 UTC the next day is shown. Grid spacing of the analysis is about $25 \mathrm{~km}$.

http://www.cnrm.meteo.fr/aladin/ in the World Wide Web for more information on the large ALADIN community). Two different ALADIN configurations are investigated. The first configuration, named ALADIN-VIENNA, is the operational configuration at the Austrian national weather agency with about $10 \mathrm{~km}$ horizontal grid spacing. The second configuration is a non-hydrostatic configuration, named ALADIN-nh, with $4 \mathrm{~km}$ horizontal grid spacing. In a first validation step simulated precipitation fields will be compared with observed precipitation. Additionally, we will apply an indirect approach suitable for high-resolution precipitation fields (proposed, e.g. in Binder and Schär, 1996): hydrologic simulations with a distributed hydrologic model, namely the model WaSiM-ETH (spatial resolution $\Delta x=$ $500 \mathrm{~m}$ ), and comparison of simulated and observed river discharges at Alpine catchment outlets. The main advantage of this indirect approach is that river discharge is a well gaugeable quantity and is sensible to amount and distribution of catchment precipitation. We focus our investigations on the Ticino-Verzasca-Maggia (TVM) watershed well investigated within the Mesoscale Alpine Programme (e.g. Bougeault et al., 2001) and the RAPHAEL project (Bacchi and Ranzi, 2000).

On the assumption that ALADIN provides perfect precipitation fields with $10 \mathrm{~km}$ and $4 \mathrm{~km}$ grid spacing as input to WaSiM-ETH, which is also assumed perfect at $500 \mathrm{~m}$ grid spacing, the performance of simulated runoff will improve with increasing resolution of the precipitation fields. This is because of the scale difference between the precipitation grid and the numerical grid of WaSiM-ETH. Estimation of total rates of watershed precipitation improves with grid spacing reduction from 10 to $4 \mathrm{~km}$. Additionally, spatial variability will increase with higher resolution and, thus, because of nonlinear hydrologic processes, the runoff simulations will improve with increasing resolution. Investigations of the impact of spatial and temporal rainfall variability on simulated runoff at all catchment scales are reported in Dawdy and Bergman (1969); Beven and Hornberger (1982); Milly and Eagleson (1988); Mutzner (1991); Obled et al. (1994); Faures et al. (1995); Jasper et al. (2000); Arnaud et al. (2002). Therefore, we have to consider the different variability of precipitation fields at different scales in validation studies.

Another issue is effective resolution of numerical results. For stability reasons, the numerical schemes of meteorological models suppress smallest waves (e.g. Grasso, 2000; Harris et al., 2001). On the other hand Ahrens et al. (2001a) show that ALADIN-nh simulations overestimate spatial variability of precipitation if compared to radar data in the area of interest. Therefore, effective resolution of simulated precipitation fields is smaller than the grid-scale implies. Consequently the smallest scales of ALADIN simulations have to be interpreted cautiously.

In the next section the investigated precipitation events and the area of interest are introduced. In Sect. 3 we present ALADIN and the meteorological simulation experiments. Section 4 discusses the validation environment, the available observational data, and introduces the hydrologic model WaSiM-ETH. The results are presented and discussed in Sect. 5 followed by some concluding remarks.

\section{Precipitation events and area of investigation}

Target area of the reported investigations is the alpine "Ticino-Verzasca-Maggia" (TVM) watershed (total area: 


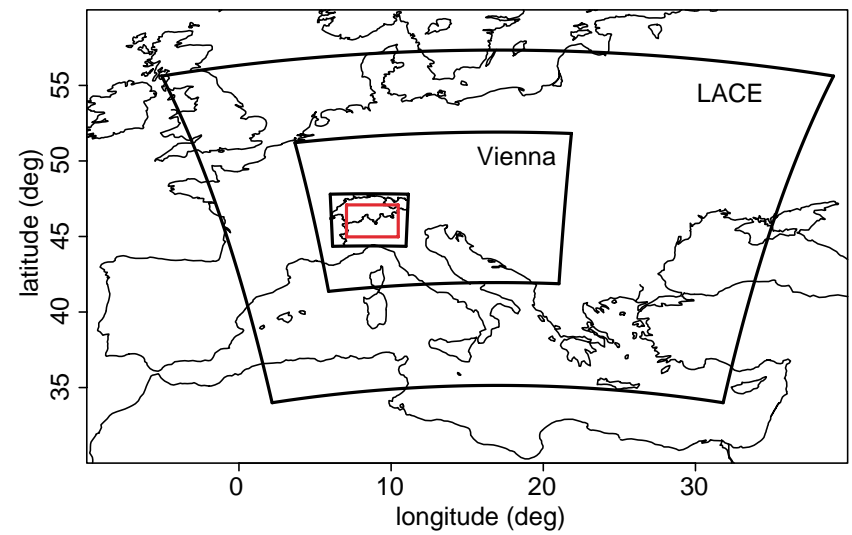

Fig. 2. Simulation domains of ALADIN-LACE, ALADINVIENNA and ALADIN-nh. The inner-most frame marks the area shown in Fig. 1.

$2627 \mathrm{~km}^{2}$ ) upstream of Lago Maggiore close to the SwissItalian border as indicated in Fig. 1. This area has been intensively studied within the Mesoscale Alpine Programme (MAP) (e.g. Bougeault et al., 2001) and its sub-project RAPHAEL (Bacchi and Ranzi, 2000). The watershed has a complex orography with elevations between 200 and 3400 $\mathrm{m}$ ASL and a mean slope of about $30^{\circ}$. Climatic conditions are characterized on the one hand by exceptional precipitation amounts and intensities (Frei and Schär, 1998) leading to relatively frequent flood events and, on the other hand, by moderately extreme seasonal drought periods.

Here, we focus on three heavy precipitation events: the RAPHAEL TT4 (27 June, 00:00 UTC, to 30 June, 00:00 UTC, 1997) flood event, and the MAP events IOP2b (19 September, 00:00 UTC, to 22 September, 00:00 UTC, 1999) and IOP3 (25 September, 12:00 UTC, to 28 September, 00:00 UTC, 1999). All of these events are characterized by strong persistent low-level moist flow from the Mediterranean Sea impinging on the Alpine barrier in the mountainous backdrop of the Lago Maggiore region causing heavy orographic precipitation over the TVM basin. The events are categorized as "major rain events owing to broad-scale ascent of moist flow over a high mountain barrier" (Smith, 1979) with embedded convection. More detailed descriptions of the synoptic situations can be found on the World Wide Web pages of the MAP Data Centre, http://www.map.ethz.ch.

\section{ALADIN configurations}

ALADIN is an atmospheric modeling system developed by a collaboration of several national weather agencies for operational short-range weather forecasts on a regional scale (e.g. Horányi et al., 1996; Bubnova et al., 1995; Cordoneanu and Geleyn, 1998; Gerard, 2000, and in the World Wide Web at www.cnrm.meteo.fr/aladin/). ALADIN is a spectral LAM with a terrain-following hybrid pressure coordinate, a semiimplicit semi-Lagrangian advection scheme and comprehensive physics (cf. Gerard, 2000). The different parameteri- zations of physical processes are a boundary layer and turbulence formulation following Louis et al. (1982), shallow convection parameterization (Geleyn, 1987), gravity wave drag, the ISBA soil-vegetation scheme (Noilhan and Planton, 1989), and a radiation scheme according to Ritter and Geleyn (1992). A diagnostic cloudiness and large-scale precipitation scheme with Kessler-type cloud microphysics (Kessler, 1969) is implemented.

Molinari and Dudek (1992) conclude that models with grid spacing less than $2-3 \mathrm{~km}$ can successfully resolve deep convection. Benoit et al. (2002) report on simulations with $3 \mathrm{~km}$ grid spacing and without deep convection parameterization scheme that an underestimate precipitation amounts. They conclude that a deep-convection parameterization scheme is still required. Therefore, we apply a deep convection scheme, namely a modified Bougeault (1985) scheme, in our ALADIN simulations. This scheme and its pros and cons in very high resolution modeling are discussed in Bougeault and Geleyn (1989) and Gerard (2001). Important aspects of the implementation of the modified Bougeault-scheme are (a) the utilization of large-scale precipitation and deepconvection scheme at the same grid points, (b) the reduction of large-scale moisture-convergence provided to the deepconvection scheme depending on mesh size and vertical convergence of the large-scale precipitation flux and (c) the affection of the large-scale through detrainment of cloud variables to the environment, and thus establishing a feed back mechanism. These characteristics qualify the modified Bougeault-scheme as a hybrid scheme in the nomenclature of Molinari and Dudek (1992).

We investigate simulations of heavy precipitation events TT4, IOP2b and IOP3 with ALADIN (version 11.2) in two configurations. The first one is the hydrostatic configuration with about $10 \mathrm{~km}$ horizontal grid spacing, called ALADINVIENNA, that is operational at the Austrian national weather agency ZAMG. ALADIN-VIENNA has $133 \times 117$ horizontal grid points, 31 vertical levels and time steps of $10 \mathrm{~min}$. ALADIN-VIENNA simulations are nested into ALADINLACE forecast data as given by the RC LACE Archiving Centre, ZAMG, Vienna. ALADIN-LACE data is available with a six-hourly resolution. ALADIN-LACE is nested into operational global ARPEGE model forecasts of METEO FRANCE, Toulouse. Figure 2 shows the domains of the ALADIN-VIENNA and ALADIN-LACE simulations.

The second configuration, called ALADIN-nh, is a nonoperational non-hydrostatic configuration with $4 \mathrm{~km}$ horizontal grid spacing $(97 \times 97$ horizontal grid points, 31 vertical levels), 90-s time steps, and adjusted horizontal diffusion parameters. The $4 \mathrm{~km}$ simulations are nested into the ALADINVIENNA results with hourly update of lateral boundaries. More details on the experimental set up are given in Ahrens et al. (2001b). Because of the higher grid resolution the resolution of physical processes is improved. For example, maximum elevation of orography increases by $500 \mathrm{~m}$ to about $4000 \mathrm{~m}$ ASL in the inner area shown in Fig. 2 (also shown in Fig. 1). Application of nested ALADIN-nh simulations is physical downscaling of ALADIN-VIENNA output by one- 


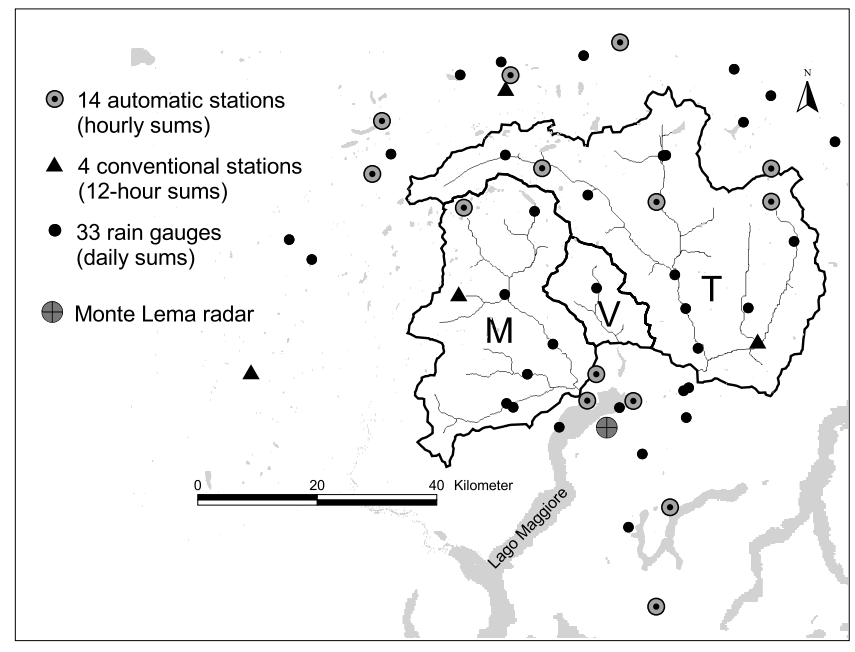

Fig. 3. Locations of meteorological stations in and around the Ticino-Verzasca-Maggia (T, V, M) watershed applied in hydrologic simulations and the Swiss Monte Lema radar. The precipitation observation frequency is indicated.

way coupling.

The events are simulated as sequences of 18-h forecasts with model initialization at 00:00 and 12:00 UTC. To account for spin-up of model numerics, the first six hours of each forecast are not considered. The western and eastern lateral boundaries of the ALADIN-nh domain intersect regions with steep orography. Here the method of coupling is particularly important. Within a coupling zone of eight grid lengths the values of the host model variables are interpolated to the grid of the nested model (introduction of features related to the finer orography and preservation of vertical structures of the host model, e.g. planetary boundary displacement) and a Davies and Kallberg relaxation scheme (Davies, 1976; Radnoti, 1995) is applied. The problem is further reduced by our selection of precipitation events with the southerly flow component dominating.

\section{Validation environment}

The goal is to help the validation of ALADIN-VIENNA and ALADIN-nh. In this study we concentrate on time sequences of hourly-accumulated high-resolution precipitation forecasts in the TVM watershed for three heavy precipitation events. One validation step is direct comparison of simulated with observed precipitation. The main problems related to this approach have already been discussed in the introduction.

Precipitation observations are available from a relatively dense surface network of rain stations and from the Swiss Monte Lema radar. Figure 3 shows the spatial distribution of the meteorological stations used in the hydrologic simulations. Most of these stations provide precipitation data only as daily sums. Thus, in order to obtain hourly precipitation amounts the stations recording high temporal resolution
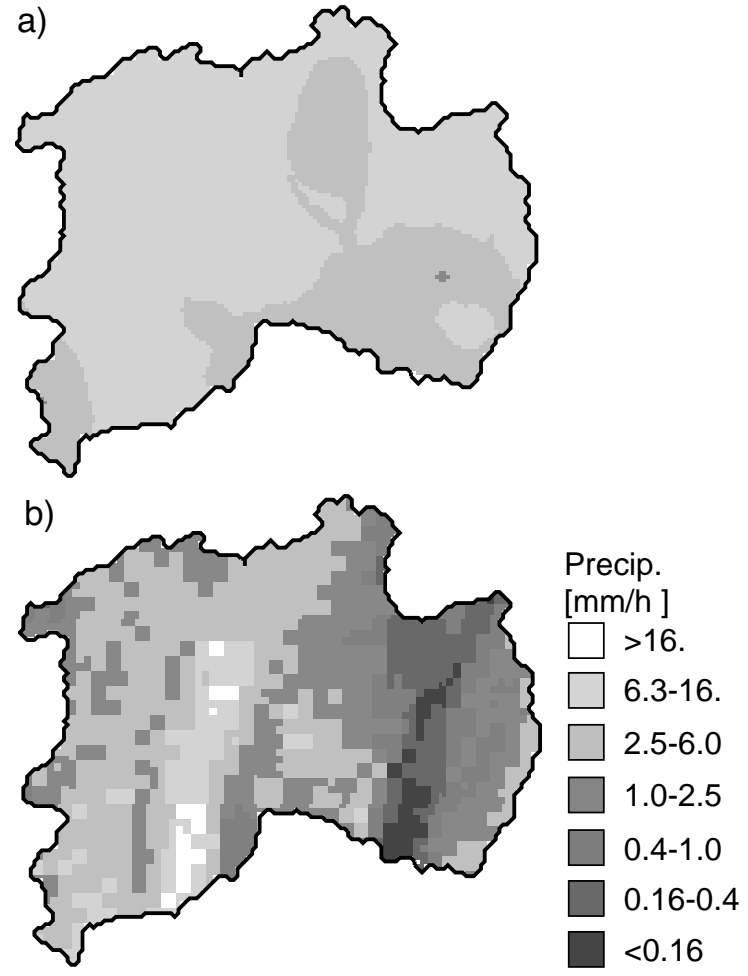

Fig. 4. Hourly accumulated precipitation fields for 20 September $1999,12: 00$ to $13: 00 \mathrm{UTC}$ in $\mathrm{mm} / \mathrm{h}$ as derived from (a) rain gauge station data and (b) from radar data in the TVM watershed.

are used to estimate rainfall for the stations providing daily sums. This is done by, firstly, an inverse distance weighting (IDW) interpolation of high-frequency data to the locations of low-frequency stations and, secondly, scaling of the hourly interpolated values to the observed low-frequency precipitation sums. Afterwards the precipitation data are corrected for wind-induced losses and interpolated to the numerical grid of WaSiM-ETH using a combined altitude-dependent and IDW interpolation scheme. Figure 4a shows an example of a precipitation field derived from the station data and Fig. 5a shows a sequence of mean precipitation rates for the TVM watershed.

Another precipitation product from surface rain stations available for IOP2b and IOP3 is provided by Frei and Häller (2001). Their precipitation analysis has a spatial resolution of about $25 \mathrm{~km}$ and a daily temporal resolution; this is based on an algorithm described in Frei and Schär (1998) which uses local area means in the area surrounding the analysis grid points. Their algorithm does not correct the rain station data and there is no altitude regression. Hence, it is consistent that the Frei and Schär (1998) values for the TVM watershed are generally smaller than the values using the algorithm described above. Figures 1 and 5 show examples. As discussed previously, this product is very useful for large-scale validation approaches but of minor significance to this study.

The Swiss Monte Lema radar is positioned close to the 
TVM watershed (cf. Fig. 3) and is therefore in an ideal position regarding our investigations. Effective resolution and quality (clutter, mountain shielding) decrease with increasing distance from the radar. Here, we use hourly accumulated radar precipitation. In the investigated events, radar derived precipitation amounts are generally smaller than those derived from rain gauge stations (cf. Figs. 4, 5a and Table 1). Nevertheless, there is no alternative source of kilometer-scale precipitation information. In Fig. 4 the patterns of interpolated station data and of radar data are compared. The differences illustrate the problems of a validation approach based on observed precipitation data.

A promising indirect validation approach can be made by hydrologic simulation. Simulated and observed precipitation fields are used as input to hydrologic simulations and the results can be compared with observed runoff rates at the watershed outlets. Runoff observations are very robust in comparison with precipitation observations and it is shown below that hydrologic simulations are sensitive to precipitation input in the investigated events.

In the following we present sensitivity experiments with the grid-based hydrologic catchment model WaSiM-ETH (Schulla, 1997; Jasper, 2001). Sequences of hourly accumulated observed, re-scaled and simulated precipitation fields are used as input. Further, less relevant meteorological variables are taken from observations. All meteorological input is interpolated onto the hydrological grid $(500 \mathrm{~m}$ grid spacing) using bi-cubic spline interpolation (for simulated and radar-derived precipitation fields) or a combined altitudedependent inverse distance weighting scheme (for surface observations). The hydrologic model WaSiM-ETH has been calibrated by continuous runoff modeling in the target watershed for the period 1993 to 1996 and validated for the period 1997 to 2000 driven by surface observations. There has been no re-calibration for the flood events investigated and the sensitivity experiments are initialized as time slice experiments. Figure $5 \mathrm{~b}$ compares runoff simulation results based on input data from rain stations or radar with observed discharge. Using corrected and interpolated rain station data leads to better results than radar data input as radar data underestimates precipitation and simulated runoff is too small.

We have already argued in the introduction that interpretation of the smallest scales of ALADIN simulations should be done with caution. An appropriate way is to upscale the simulated precipitation fields. Typically, it is accepted that LAMs have skill at horizontal wavelengths of about $4 \Delta x$ and above. We consider this by averaging consecutively onto a grid with 40 and $16 \mathrm{~km}$ grid spacing for ALADIN-VIENNA and ALADIN-nh, respectively.

Also, we have already mentioned that the performance of a hydrologic simulation with perfect precipitation input with $40 \mathrm{~km}$ resolution will be inferior to a simulation with perfect input with $16 \mathrm{~km}$ or even with $1 \mathrm{~km}$ resolution. Considering this we apply stochastic downscaling to a $1 \mathrm{~km}$ grid. This stochastic downscaling scheme is described in Ahrens (2003) and is based on a scale-invariance concept. It is an example of micro-canonical multiplicative cascade models
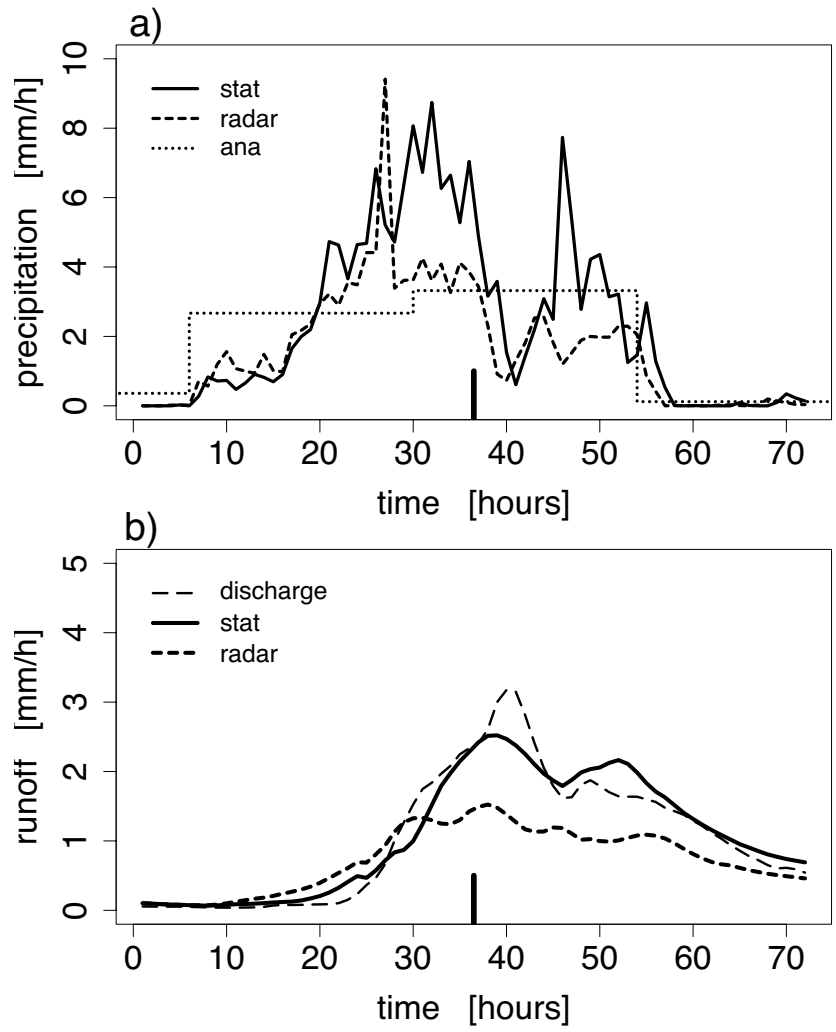

Fig. 5. TVM watershed-mean time series of (a) precipitation and (b) runoff rates during event IOP2b. Precipitation time series of corrected rain gauge (stat) and radar (radar) observations and as analyzed (ana) by Frei and Häller (2001) are shown. Hydrographs are simulated with rain gauge (stat) and radar data (radar) input. Additionally, observed runoff (discharge) is given. Hour 13 of 20 September 1999, is indicated by a bold tick mark.

(cf. Marshak et al., 1994; Menabde and Sivapalan, 2000) and is successfully applied in Ahrens (2003) in up- and downscaling experiments with radar data in the TVM watershed. Necessary input for this scheme are the coarse-grid precipitation fields from which, apart from grid point values, the spatial variance of directional fluctuations have to be estimated (this is done here for the total area shown in Fig. 1). Additionally, directional scaling exponents have to be prescribed. These determine the spatial variability of fluctuations at all smaller scales relative to the variability at the input scale. With known variances, the fluctuation fields at all scales can be simulated stochastically and afterwards the coarse-grid field can be readily downscaled applying these fluctuations. Here, following Ahrens (2003), for the investigated events it is reasonable to assume an isotropic stochastic downscaling scheme with scaling exponents prescribed to 0.3 .

Figures 6 and 7 show examples of simulated, upscaled, and downscaled hourly accumulated precipitation fields for 20 September 1999, 12:00 to 13:00 UTC. Since the resolution of the upscaled ALADIN-VIENNA field is coarse in comparison with the TVM watershed, it is difficult to estimate a reliable watershed-mean value. Additionally, upscal- 
a) ALADIN-VIENNA dx=10km

b) $d x=40 \mathrm{~km}$

c) $d x=1 \mathrm{~km}$
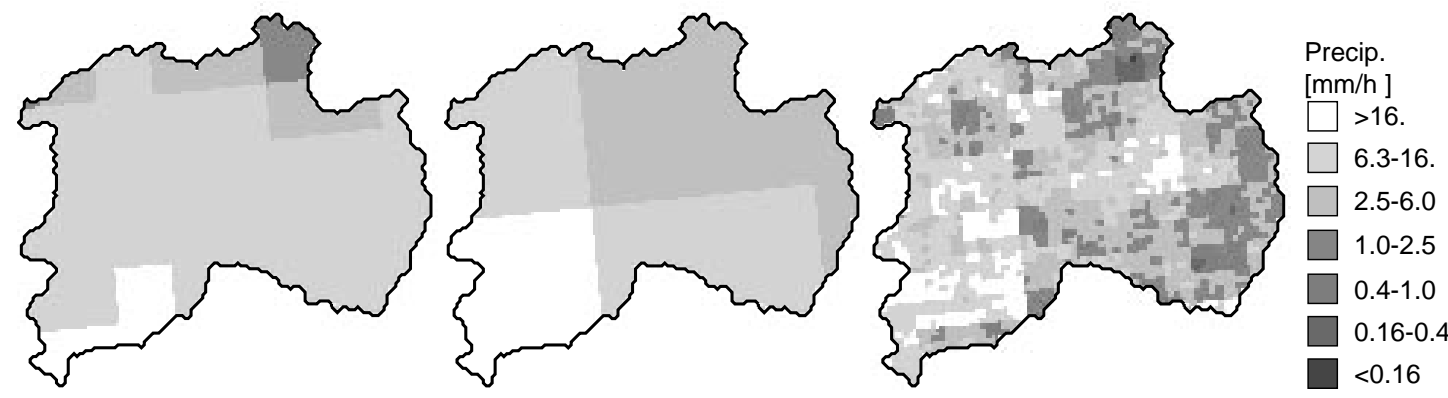

Fig. 6. Hourly accumulated precipitation products by ALADIN-VIENNA for 20 September 1999, 12:00 to 13:00 UTC in mm/h, (a) the simulated precipitation field with numerical grid spacing of $10 \mathrm{~km}$, (b) an upscaled version on a grid with $40 \mathrm{~km}$ grid spacing and (c) a stochastically downscaled field with $1 \mathrm{~km}$ grid spacing.
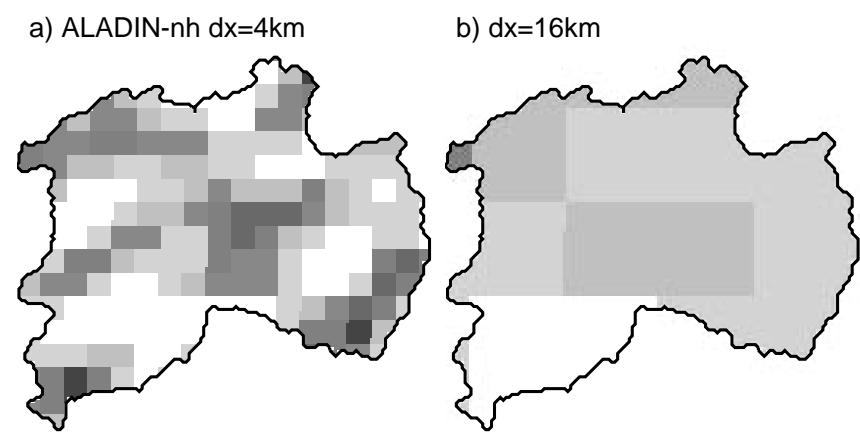

c) $d x=1 \mathrm{~km}$

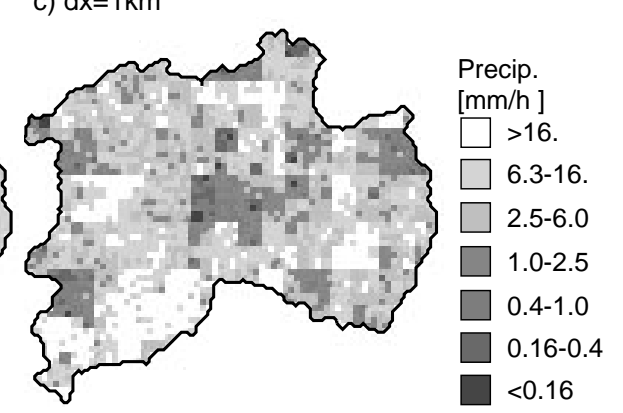

Fig. 7. Same as Fig. 6, but for ALADIN-nh products with (a) the original grid with $4 \mathrm{~km}$, (b) a coarse grid with $16 \mathrm{~km}$ and (c) a fine grid with $1 \mathrm{~km}$ grid spacing.

ing reduces spatial variability (and in consequence temporal variability). Downscaling re-introduces variability and allows a comparison of the precipitation fields at the same grid scale (cf. Figs. 4, 6, and 7).

\section{Results and discussion}

Figures 8a and 9a show the TVM-mean time series of simulated precipitation rates for event IOP2b. The effect of up- and downscaling is more pronounced in the case of ALADIN-VIENNA than of ALADIN-nh (cf. Table 1). ALADIN generates most of the precipitation upwind of mountain ridges as they are represented in the model orography. This is exemplified in Figs. 10 and 11. Up- and downscaling is mass conserving within the coarse grid cells (40 and $16 \mathrm{~km}$ grid lengths for ALADIN-VIENNA and ALADIN$\mathrm{nh}$, respectively). But, in the upscaling step, precipitation is averaged across the main Alpine crest (along the northern watershed boundary) which represents the weather divide in the simulations. As a result, the TVM-mean precipitation amount is reduced. Because of better approximation of watershed boundaries with the $16 \mathrm{~km}$ grid, the averaging effect is smaller in this case.
The total amount of precipitation is larger with ALADINnh than with ALADIN-VIENNA. The event- and TVMmean precipitation amount is larger by $13 \%$ before and by $28 \%$ after upscaling. The event-mean precipitation amount in the area shown in the Figs. 10 and 11 is larger by only $8 \%$.

The timing of peaks in the ALADIN-nh and ALADINVIENNA simulations is similar. For example, the maximum of the largest peak is simulated at noon the second day of the event (hours 35 to 40). The precipitation time series estimated from rain gauge data (Fig. 5a) shows a slightly smaller peak with its maximum shifted to the morning hours. A further large peak is indicated by rain gauge data the following night. This double-peak structure is revealed by the radar data but with a clearly smaller second peak, a smaller overall precipitation amount, and an isolated spike in the first peak. Because of the low temporal resolution, this double peak cannot be resolved in the precipitation analysis done by Frei and Häller (2001). The simulations show additional peaks: one in the morning of the first day (hour 5) and one at forenoon of the third day (hours 55 to 60). The first cannot be found in the observational data and the second is too small and too late to correspond to the second peak in the observations. But this statement is not conclusive because of the obvious problems with radar data and the small number of hourly reporting rain 
a)

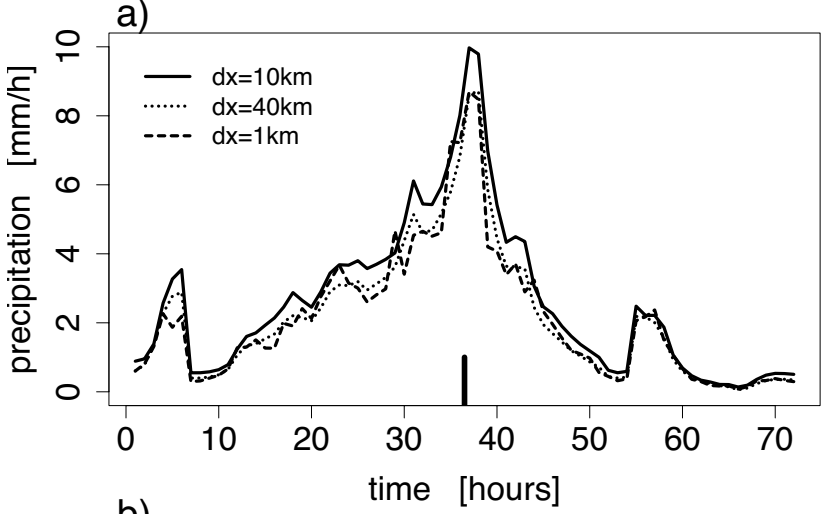

b)

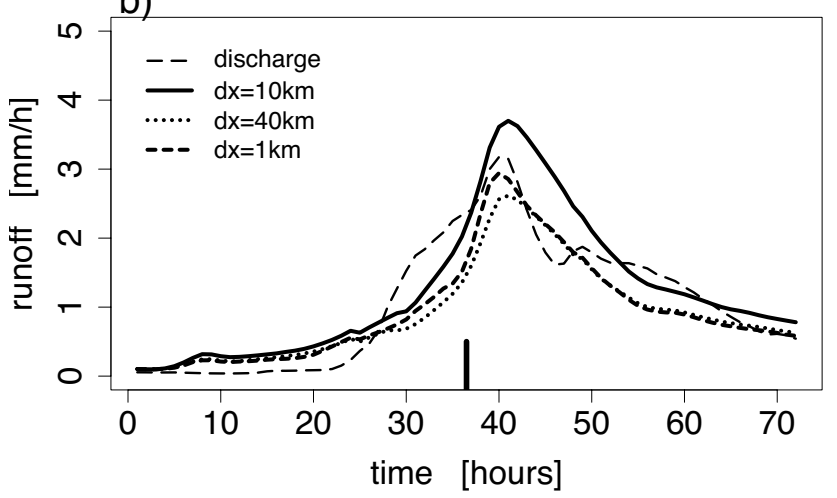

Fig. 8. Same as Fig. 5, but showing results with ALADIN-VIENNA precipitation products: raw forecast with $10 \mathrm{~km}$, spatially aggregated forecast with $40 \mathrm{~km}$, and downscaled forecast with $1 \mathrm{~km}$ grid spacing.

stations in the watershed.

Figures $9 b, 8 b$, and $5 b$ compare time series of simulated runoff with different precipitation inputs with the observed hydrograph at the watershed outlets. There is also a doublepeak structure in observed runoff. But in the runoff simulation with rain station derived precipitation input, the first peak is too small and the second peak is too large in comparison with the observed hydrograph. Obviously, radar data underestimates precipitation for this event - at least in units of simulated runoff. There is no pronounced double-peak in the simulated runoff time series simulated with ALADIN input.

Approximation of peak height and total observed discharge is rather good by runoff simulations with ALADINVIENNA input. The runoff simulation, which applies the original precipitation simulations, overestimates peak and total runoff by about $20 \%$ (cf. Fig. 7 and Table 1). Upscaling simulated precipitation fields reduces precipitation input by $16 \%$ and simulated runoff by $25 \%$. Of course, runoff decreases because of the decrease in precipitation amount but also because of the reduction of spatial and temporal precipitation variability by averaging in the upscaling process. This is due to the non-linear response of the hydrologic processes parameterized by WaSiM-ETH. Spatial downscaling re-introduces variability and, hence, in-
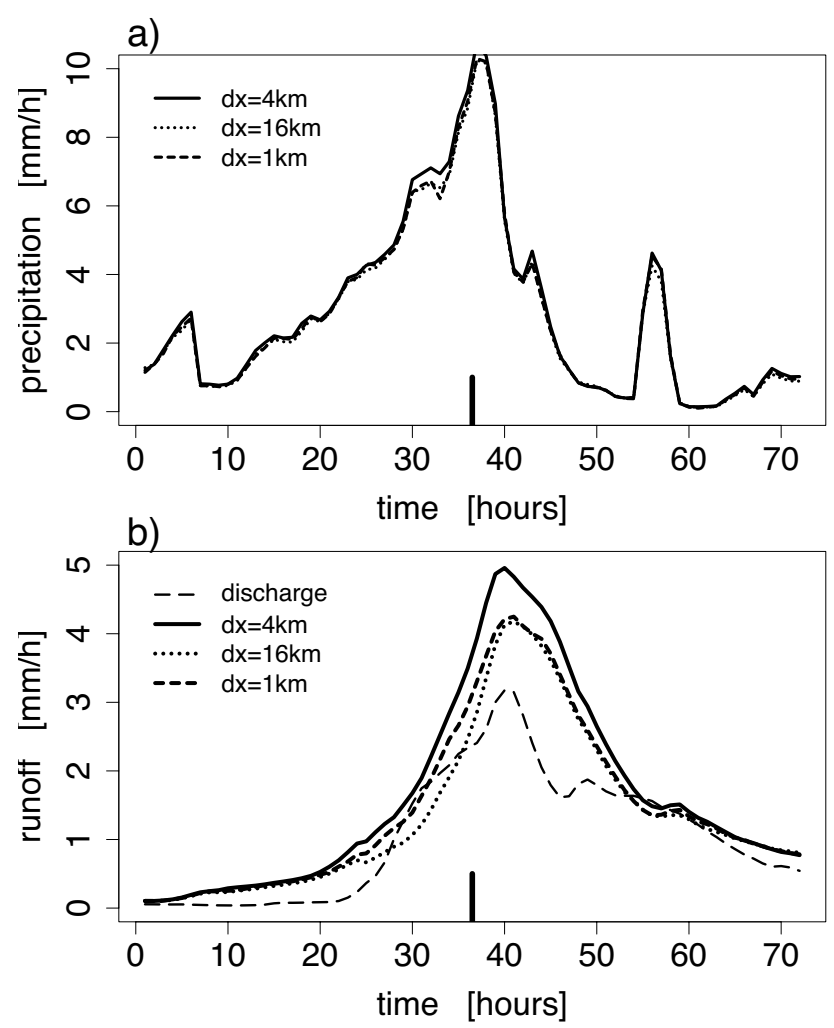

Fig. 9. Same as Fig. 5, but showing results with ALADIN-nh precipitation products: raw forecast with $4 \mathrm{~km}$, spatially aggregated forecast with $16 \mathrm{~km}$, and downscaled forecast with $1 \mathrm{~km}$ grid spacing.

creases simulated runoff (in spite of a small additional decrease of the precipitation amount by $1 \%$ ). Timing and height of the peak runoff rate, simulated with stochastically downscaled ALADIN-VIENNA precipitation forecasts, approximates the observed discharge very well. Nevertheless, ALADIN-VIENNA seems to underestimate precipitation between the hours 20 and 30 of event IOP $2 b$. This is indicated by the convex shape with larger runoff values of the observed discharge sequence and the concave shape with lower values in the simulated sequence. But, overall, ALADINVIENNA precipitation is a good predictor of WaSiM-ETH input in event IOP2b and the TVM watershed in spite of some problems in temporal structure. Precipitation amount is slightly too large at the original grid and seems to be slightly too small after up- and downscaling. Here, a remark about the downscaling method is necessary. Our method neglects small-scale precipitation persistence in time. It is assumed that the effect of small-scale persistence is small for time steps of one hour; but a consistent time and space downscaling scheme has the potential further to increase simulated runoff and thus to improve the ALADIN-VIENNA results.

Precipitation generated by ALADIN-nh simulations clearly overestimates peak runoff rate and total runoff (by about 50\%, cf. Fig. 9 and Table 1). Upscaling of ALADINnh precipitation onto a grid with $16 \mathrm{~km}$ grid spacing reduces 


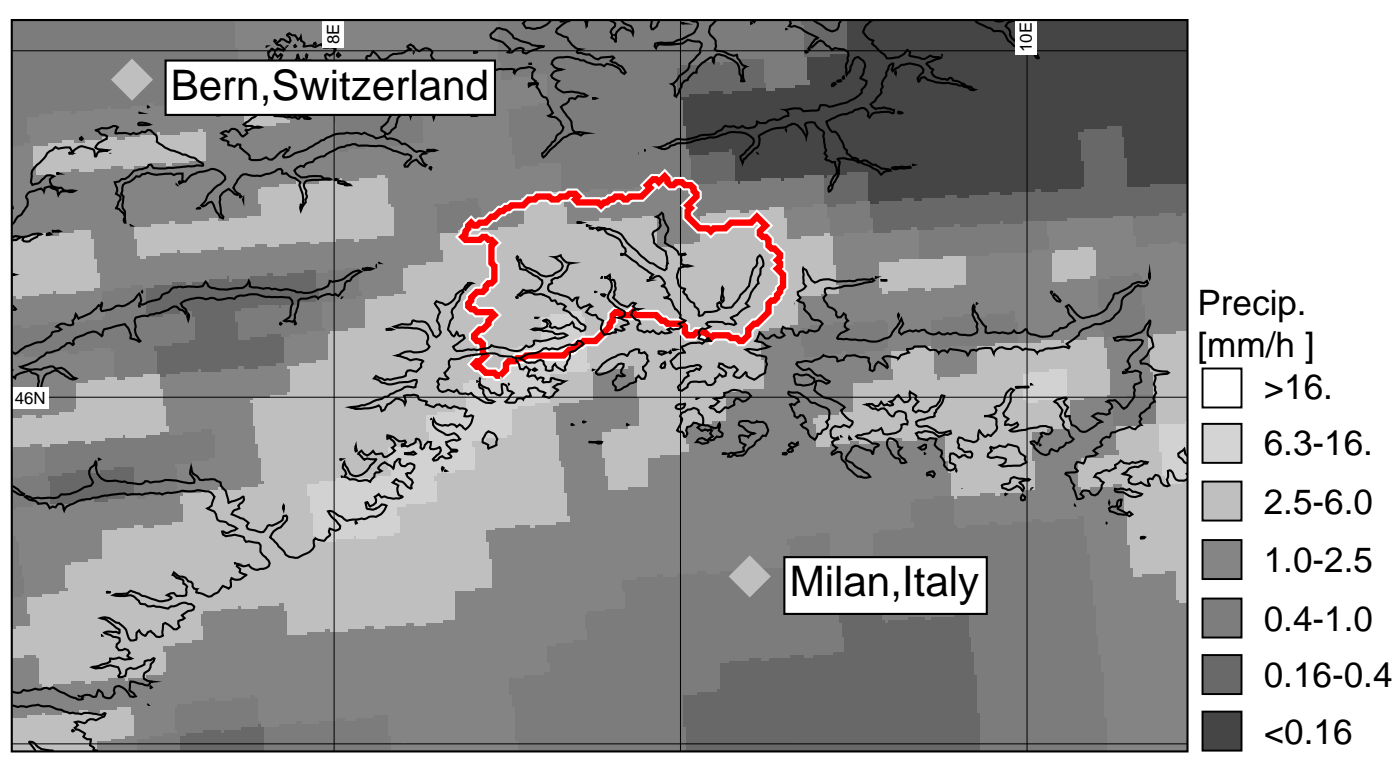

Fig. 10. Same as Fig. 1, but a precipitation field with grid spacing of about $10 \mathrm{~km}$ simulated by ALADIN-VIENNA is shown for the period 06:00 UTC at 20 September 1999 to 06:00 UTC the next day.

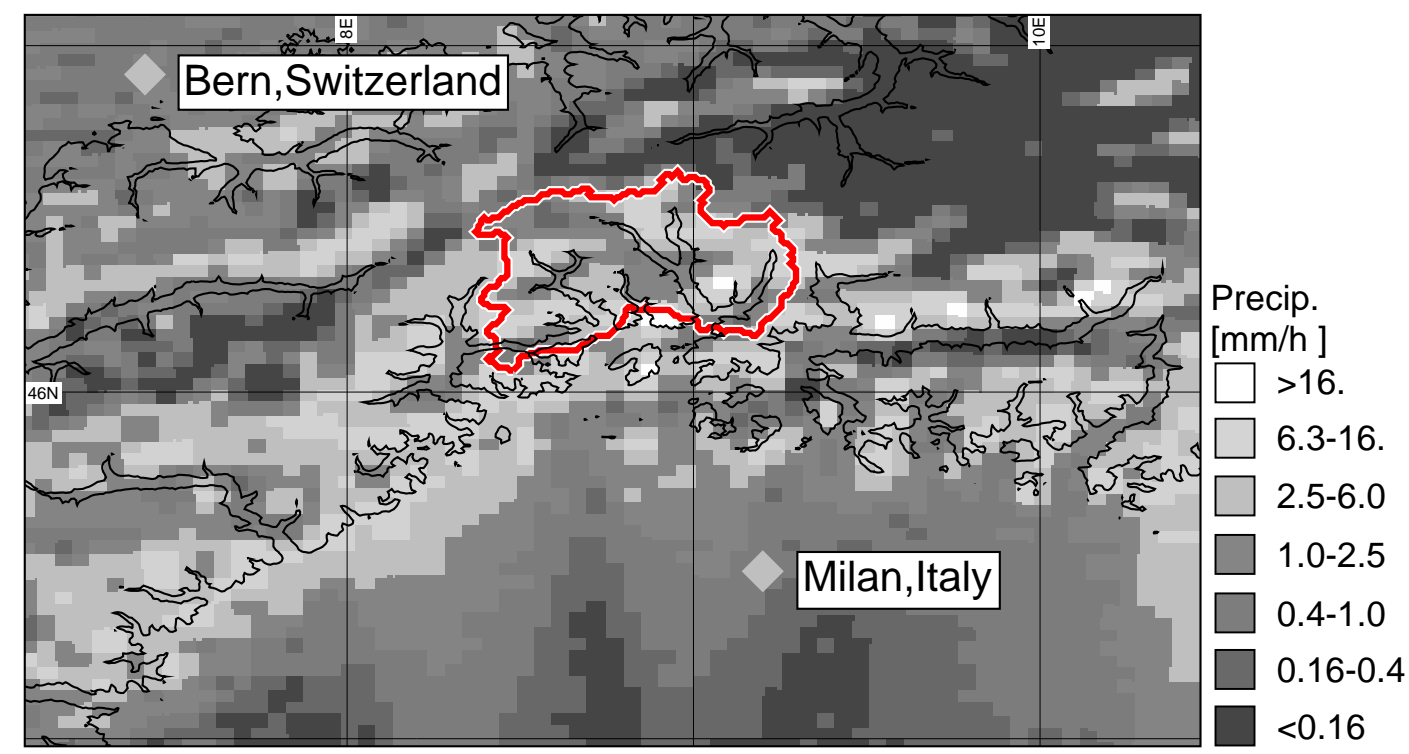

Fig. 11. Same as Fig. 10, but a precipitation field with grid spacing of about $4 \mathrm{~km}$ simulated by ALADIN-nh is shown.

precipitation amount by $5 \%$ and simulated total runoff by as much as $17 \%$. Stochastic downscaling of the upscaled ALADIN-nh fields increases runoff by $7 \%$ with a $1 \%$ change of total precipitation. This indicates that small-scale spatial variability is overestimated in ALADIN-nh simulations. Comparison of the 1-km versions of ALADIN-VIENNA and ALADIN-nh fields in Figs. 6 and 7 with the radar image in Fig. 4b supports this conclusion. Ahrens et al. (2001a) came to the same result based on variogram estimations for radar and simulated precipitation fields for the total domain in Fig. 1 but, as previously discussed, validation of spatial patterns of precipitation by direct comparison with observations is difficult.

Event TT4 basically shows the same result as IOP2b (cf. Table 1), namely that the ALADIN-VIENNA simulation is superior to the ALADIN-nh simulation. In TT4 and IOP2b with ALADIN-VIENNA the original grid precipitation amount is larger and after up- and downscaling smaller than observed by station data. ALADIN-nh precipitation is larger and well above observation after up- and downscaling. Nevertheless, the differences are smaller than the differences between rain station and radar data estimation 
of precipitation amount. The overestimation of ALADIN$\mathrm{nh}$ is more pronounced by application of hydrologic modeling. ALADIN-VIENNA precipitation is comparable with rain station precipitation and better than radar derived precipitation in units of runoff.

Interpretation of event IOP3 is difficult because of probable human water reservoir management that is not reported in the data available for the hydrologic simulations. But, temporal structure of runoff rates and comparison with observed precipitation rates (not shown) indicate that a sharp precipitation peak is underestimated by ALADIN (by more than 50\%) and show that ALADIN strongly overestimates precipitation intensity at the end of the period.

ALADIN with coarser grid resolution provides better precipitation predictors in the TVM watershed. This is disappointing since the processes leading to precipitation should be better resolved in higher-resolution simulations. What are the reasons? With $4 \mathrm{~km}$ grid spacing, the usefulness of deep convection scheme is questionable. In this scale range it is sometimes argued that it is better to switch off any deep convection parameterization and to hope that convection is resolved explicitly. We performed numerical experiments without the deep convection scheme. In these experiments, area-mean precipitation amount decreases. For example, in event IOP $2 b$, the precipitation amount in the area shown in Figs. 10 and 11 is reduced by $36 \%$ (the simulated precipitation is even smaller than the grid-scale component of ALADIN-nh simulations). But the TVM amount is reduced by only $6 \%$ and thus stays larger than the observed amount. Therefore, potential problems with the convection scheme cannot explain the lack of ALADIN-nh performance.

If we have a closer look at Figs. 10, 11 and 1 we see that precipitation is primarily simulated over upwind slopes of orography (there is a predominant southerly flow in event IOP2b). This effect is more pronounced in ALADIN-nh, with its better resolution of orography, than in ALADINVIENNA but is not justified by the precipitation analysis. Remembering that the TVM watershed is upwind of the main Alpine crest and that upscaling reduces precipitation overestimation, we conclude that ALADIN simulates relatively too much precipitation over upwind orography slopes. The authors see two potential reasons: The first one is related to the terrain-following vertical coordinate of ALADIN. Problems with this coordinate in case of steep orography are reported in the literature (e.g. Davies and Brown, 2001; Zängl, 2002). In a terrain-following coordinate system a horizontal (i.e. along coordinate surface) diffusion scheme mixes water vapor vertically in real space. Hence, too much water vapor is transported upslope at the luff side of the mountain and this could lead to overestimation of cloud condensation. A second problem of ALADIN in this context seems to be that neither cloud condensate nor precipitation are prognostic variables. This is obviously a problem at very small grid-scales: rain drops with a terminal velocity of $4 \mathrm{~m} / \mathrm{s}$ released $2000 \mathrm{~m}$ above ground can be transported horizontally by $5 \mathrm{~km}$ if a very moderate advection velocity of $10 \mathrm{~m} / \mathrm{s}$ is assumed. In ALADIN, a rain drop falls through all lower
Table 1. Total mean observed or simulated precipitation and runoff rates in mm/h. ALADIN-VIENNA (A-VIE) and ALADIN-nh (A$\mathrm{nh})$ data refer to the original and downscaled grid products

\begin{tabular}{lcccccc}
\hline & \multicolumn{3}{c}{ precipitation } & \multicolumn{3}{c}{ runoff } \\
\hline event & TT4 & IOP2b & IOP3 & TT4 & IOP2b & IOP3 \\
\hline discharge & & & & 1.0 & 1.1 & 1.2 \\
stat & 1.8 & 2.4 & 2.1 & 0.7 & 1.1 & 0.9 \\
radar & 1.2 & 1.5 & 1.6 & 0.5 & 0.7 & 0.7 \\
A-VIE $(10 \mathrm{~km})$ & 2.3 & 2.6 & 1.8 & 1.0 & 1.2 & 0.7 \\
A-VIE $(1 \mathrm{~km})$ & 1.8 & 2.1 & 1.5 & 0.8 & 0.9 & 0.5 \\
A-nh $(4 \mathrm{~km})$ & 2.7 & 2.9 & 1.8 & 1.4 & 1.7 & 0.6 \\
A-nh $(1 \mathrm{~km})$ & 2.5 & 2.8 & 1.7 & 1.2 & 1.5 & 0.6 \\
\hline
\end{tabular}

model levels within a single time step. There are indications in the literature that prognostic formulations improve Alpine precipitation fields in high-resolution modeling (Gassmann, 2002).

\section{Conclusions}

Validation of high-resolution meteorological models is a major challenge. Our goal was to assess precipitation fields simulated with ALADIN in two configurations (ALADINVIENNA with $10 \mathrm{~km}$ and ALADIN-nh with $4 \mathrm{~km}$ grid spacing) in the case of heavy precipitation events in the Alpine Ticino-Verzasca-Maggia watershed. We briefly discussed the problems associated with the validation of high-resolution precipitation simulations applying direct comparison with observational data.

If present-day distributed hydrologic models, like the WaSiM-ETH, get high-quality high-resolution precipitation input, they provide us with reasonable flood forecasts. If input quality decreases, there is a pronounced impact on flood forecast quality. This has been demonstrated for WaSiMETH applied in the TVM watershed, for example, in Bacchi and Ranzi (2000); Jasper et al. (2000) and confirmed here. Hydrologic modeling can therefore be considered as a sensible and useful evaluation tool.

Measured by simulated runoff, the performance of ALADIN-VIENNA is surprisingly good, at least for the investigated heavy precipitation events. ALADIN-VIENNA simulations are comparable with observed precipitation fields. Precipitation amounts modeled by ALADIN-nh are less accurate and there are indications that simulated spatial variability is overestimated. This unrealistic roughness of ALADIN-nh precipitation fields has already been shown in Ahrens et al. (2001a) by comparison with radar data. The reason for this dissatisfactory performance of ALADIN-nh has to be further investigated but we assume it to be related to numerical problems with steep orography and to the diagnostic parameterization of precipitation processes in ALADIN.

The results reported here are valid for three heavy precipitation events with a strong synoptic (approaching flow of 
moist air from the Mediterranean sea) and well defined orographic forcing. Events of this type are typically well simulated by meteorological models and thus investigations have to be extended using a large sample of different events in, preferably, different Alpine watersheds.

Acknowledgements. Meteorological data are provided by MeteoSwiss, the MAP Data Centre, Zürich, and Martin Hagen, DLR. Additionally, we thank Radmila Brozkova, ALADIN-LACE, Prague, and Yong Wang, ZAMG, Vienna, for their help with ALADIN. ZAMG, Vienna, gave permission to use their computing facilities and provided access to ALADIN. This paper is partly supported by the Austrian Academy of Sciences, project HÖ 22.

Topical Editor J.-P. Duvel thanks two referees for their help in evaluating this paper.

\section{References}

Adler, R. F., Kidd, C., Petty, G., M., M., and Goodman, H. M.: Intercomparison of global precipitation products: The third precipitation intercomparison project (PIP-3), Bull. Amer. Meteor. Soc., 82, 1377-1396, 2001.

Ahrens, B.: On precipitation downscaling in alpine hydrology, International Hydrological Programme, Technical Documents in Hydrology, p. 18, in press, 2003.

Ahrens, B., Karstens, U., Rockel, B., and Stuhlmann, R.: On the validation of the atmospheric model REMO with ISCCP data and precipitation measurements using simple statistics, Meteorology and Atmospheric Physics, 68, 127-142, 1998.

Ahrens, B., Seidl, H., and Jasper, K.: On the validation of ALADIN quantitative precipitation forecasts in an Alpine catchment, MAP Newsletter, 15, 57-60, 2001a.

Ahrens, B., Wang, Y., and Jasper, K.: On ALADIN quantitative precipitation forecasts in Vienna, ALADIN Newsletter, 19, 64$68,2001 b$.

Arnaud, P., Bouvier, C., Cisneros, L., and Dominguez, R.: Influence of rainfall spatial variability on flood prediction, J. Hydrology, 260, 216-230, 2002.

Bacchi, B. and Ranzi, R., (Eds): Runoff and Atmospheric Processes for Flood Hazard Forecasting and Control, Final Report to EC, Directorate General XII, Programme Environment and Climate 1994-1998. Contract ENV4-CT97-0552, Brussels, 2000.

Benoit, R., Pellerin, P., Kouwen, N., Ritchie, H., Donaldson, N., Joe, P., and Soulis, E. D.: Towards the use of coupled atmospheric and hydrologic models at regional scale, Monthly Wea. Rev., 128, 1681-1706, 2000.

Benoit, R., Schär, C., Binder, P., Chamberland, S., Davies, H. C., Desgagné, M., Girard, C., Keil, C., Kouwen, N., Lüthi, D., Maric, D., Müller, E., Pellerin, P., Schmidli, J., Schubiger, F., Schwierz, C., Sprenger, M., Walser, A., Willemse, S., Yu, W., and Zala, E.: The real-time ultrafinescale forecast support during the special observing period of the MAP, Bull. Amer. Meteor. Soc., 83, 85-109, 2002.

Beven, K. and Hornberger, G.: Assessing the effect of spatial pattern of precipitation in modelling streamflow hydrographs, Water Resour. Bull., 18, 823-829, 1982.

Binder, P. and Schär, C.: MAP design proposal. 2nd ed., Available from MAP data centre, ETH Zürich, Switzerland, 1996.

Bougeault, P.: A simple parameterization of the large-scale effects of cumulus convection, Monthly Wea. Rev., 113, 2108-2121, 1985.
Bougeault, P. and Geleyn, J.-F.: Some problems of closure assumption and scale dependency in the parameterization of moist deep convection for numerical weather prediction, Meteorology and Atmospheric Physics, 40, 123-135, 1989.

Bougeault, P., Binder, P., Buzzi, A., Dirks, R., Houze, R., Kuettner, J., Smith, R. B., Steinacker, R., and Volkert, H.: The MAP special observing period, Bull. Amer. Meteor. Soc., 82, 433-462, 2001.

Bubnova, R., Hello, G., Bernard, P., and Geleyn, J.-F.: Integration of the fully elastic equations cast in the hydrostatic pressure terrain-following coordinate in the framework of the ARPEGE/Aladin NWP system, Monthly Wea. Rev., 123, 515535, 1995.

Cherubini, T., Ghelli, A., and Francois, L.: Verification of precipitation forecasts over the alpine region using a high-density observing network, Weather and Forecasting, 17, 238-249, 2002.

Ciach, G., Morrissey, M., and Krajewski, W. F.: Conditional bias in radar rainfall estimation, J. Appl. Meteorology, 39, 1941-1946, 2000.

Cordoneanu, E. and Geleyn, J.-F.: Application to local circulations above the Carpathian-black sea area of a NWP-type meso-scale model, Contr. Atmos. Phys., 71, 191-212, 1998.

Davies, H.: A lateral boundary formulation for multi-level prediction models, Quart. J. R. Met. Soc., 102, 405-418, 1976.

Davies, L. A. and Brown, A. R.: Assessment of which scales of orography can be credibily resolved in a numerical model, Q. J. R. Meteorol. Soc., 127, 1225-1238, 2001.

Dawdy, D. and Bergman, J.: Effect of rainfall variability on streamflow simulation, Water Resour. Res., 5, 958-966, 1969.

Faures, J.-M., Goodrich, D., Woolhiser, D., and Sorooshian, S.: Impact of small-scale spatial rainfall variability on runoff modeling, J. Hydrology, 173, 309-326, 1995.

Ferretti, R., Paolucci, T., Zheng, W., Visconti, G., and Bonelli, P.: Analyses of the precipitation pattern on the Alpine region using different cumulus convection parameterizations, J. Appl. Meteorology, 39, 182-200, 2000.

Frei, C. and Häller, E.: Mesoscale precipitation analysis from MAP SOP rain-gauge data, MAP Newsletter, 15, 257-260, 2001.

Frei, C. and Schär, C.: A precipitation climatology of the Alps from high-resolution rain-gauge observations, Int. J. Climatol., 18, 873-900, 1998.

Gassmann, A.: 3d-transport of precipitation, COSMO Newsletter, 2, 113-117, 2002.

Geleyn, J.-F., Use of a modified Richardson number for parameterizing the effect of shallow convection, J. Meteor. Soc. Japan, Special NWP symposium issue, 1987.

Gerard, L.: Physical parameterizations in ARPEGE-ALADIN_version 1.0, available at http://www.cnrm.meteo.fr/aladin/ MODELES/DOC_modeles.html, 2000.

Gerard, L.: Physical Parameterisations for a High Resolution Operational Numerical Weather Prediction Model, Ph.D. Thesis, Brussels Free University, 2001.

Grasso, L. D.: The differentiation between grid spacing and resolution and their application to numerical modeling, Bull. Amer. Meteor. Soc., 81, 579-580, 2000.

Harris, D., Foufoula-Georgiou, E., Droegemeier, K., and Levit, J.: Multiscale statistical properties of a high-resolution precipitation forecast, J. of Hydrology, 2, 406-418, 2001.

Horányi, A., Ihász, I., and Radnóti, G.: ARPEGE/ALADIN: A numerical weather prediction model for Central-Europe with the participation of the Hungarian Meteorological Service, Időjárás, 100, 277-301, 1996. 
Jasper, K.: Hydrological modelling of Alpine river catchments using output variables from atmospheric models, Ph.D. Thesis, ETH Zürich, no. 14385, 2001.

Jasper, K., Gurtz, J., Lang, H., Kaufmann, P., and Binder, P.: Flood forecast by coupling atmospheric and hydrologic models at regional scale, in: PIK Report No. 65, European Conf. on Advances in Flood Research, Proc. Vol. 1, pp. 276-284, 2000.

Kessler, E.: On the distribution and continuity of water substance in atmospheric circulations, Meteor. Monogr., 10, 1-84, 1969.

Lau, K.-M., Kim, J. H., and Sud, Y.: Intercomparison of hydrologic processes in AMIP GCMs, Bull. Amer. Meteor. Soc., 77, 22092227, 1996.

Louis, J.-F., Tiedke, M., and Geleyn, J.-F.: A short history of the PBL parameterizationas at ECMWF, Proc. of the ECMWF workshop on planetary boundary parameterization, Reading, 25-27 Nov. 1981, pp. 59-80, 1982.

Marshak, A., Davis, A., Cahalan, R. F., and Wiscombe, W. J.: Bounded cascade models as non-stationary multifractals, Phys. Rev., E49, 55-69, 1994.

Menabde, M. and Sivapalan, M.: Modeling of rainfall time series and extremes using bounded random cascades and Levy-stable distributions, Water Resour. Res., 36, 3293-3300, 2000.

Milly, P. and Eagleson, P.: Effects of storm scale on surface runoff volume, Water Resour. Res., 24, 620-624, 1988.

Molinari, J. and Dudek, M.: Parameterization of convective precipitation in mesoscale numerical models: A critical review, Monthly Wea. Rev., 120, 326-344, 1992.

Mutzner, H.: The significance of areal rainfall distribution for flows from a very small urban drainage catchment, Atmos. Res, 27, 99-107, 1991.
Noilhan, J. and Planton, S.: A simple parameterization of land surface processes for meteorological models, Monthly Wea. Rev., 117, 536-549, 1989.

Obled, C., Wendling, J., and Beven, K.: The sensitivity of hydrological models to spatial rainfall patterns: An evaluation using observed data, J. Hydrology, 159, 305-333, 1994.

Radnoti, G.: Comments on "A spectral limited-area formulation with time-dependent boundary conditions applied to the shallowwater equations", Monthly Wea. Rev., 123, 3122-3123, 1995.

Ritter, B. and Geleyn, J.-F.: A comprehensive radiation scheme for numerical weather prediction models with potential applications in climate studies, Monthly Wea. Rev., 120, 303-325, 1992.

Rubel, F. and Hantel, M.: Correction of daily rain gauge measurements in the Baltic Sea drainage basin, Nordic Hydrology, 30, 191-208, 1999.

Schär, C.: Alpine numerical weather prediction 2000-2020: A look back to the future, MAP Newsletter, 14, 6-12, 2001.

Schulla, J.: Hydrologische Modellierung von Flussgebieten zur Abschätzung der Folgen von Klimaänderungen, Ph.D. Thesis, ETH Zürich, Zürcher Geographische Schriften, Heft 69, 1997.

Smith, R.: The influence of mountains on the atmosphere, Adv. Geophys., 21, 87-230, 1979.

Tustison, B., Harris, D., and Foufoula-Georgiou, E.: Scale issues in verification of precipitation forecasts, J. Geophys. Res., 106, 11775-11 784, 2001.

Zängl, G.: An improved method for computing horizontal diffusion in a sigma-coordinate model and its application to simulations over mountainous topography, Monthly Wea. Rev., 130, 1423$1432,2002$. 